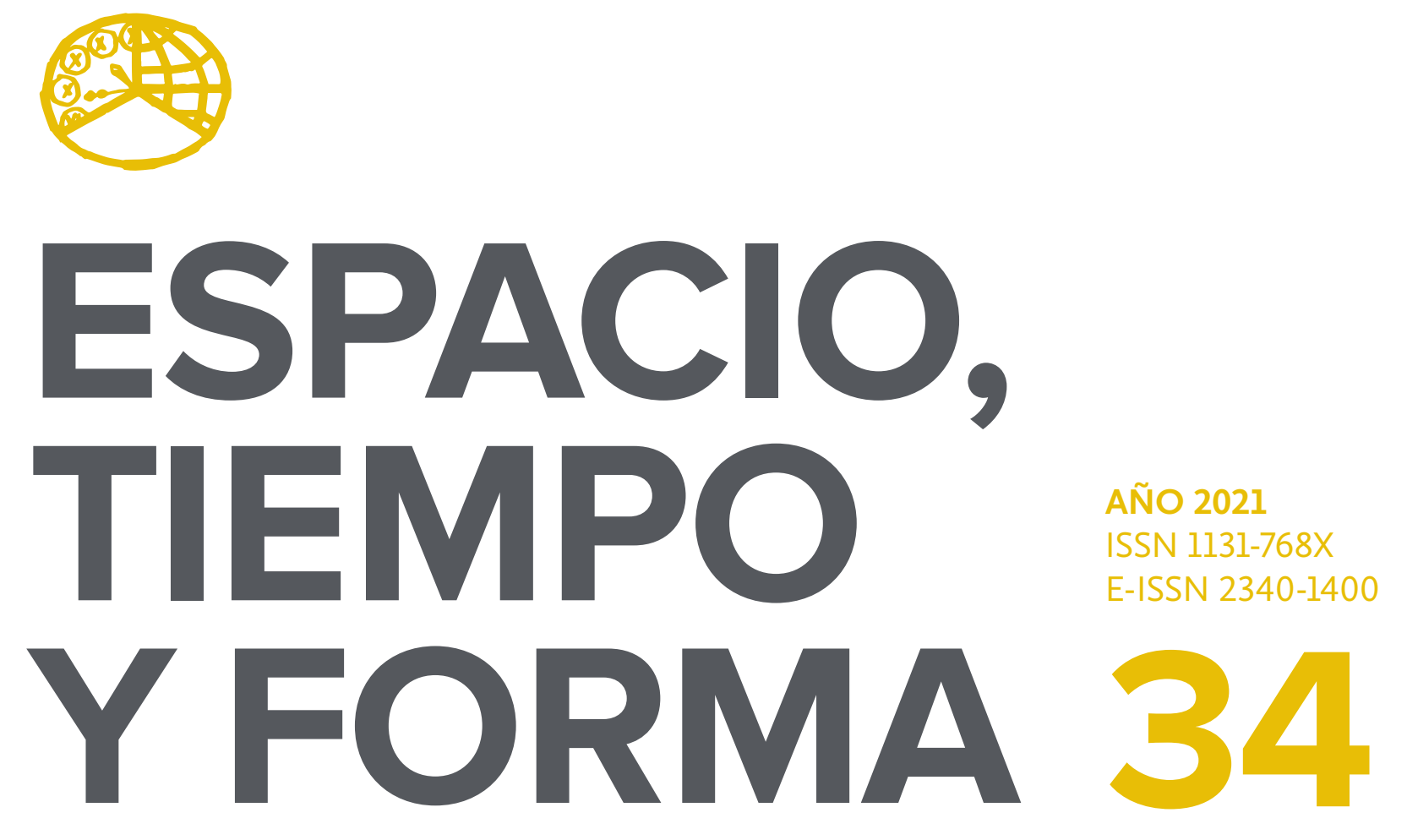

SERIE IV HISTORIA MODERNA

REVISTA DE LA FACULTAD DE GEOGRAFÍA E HISTORIA

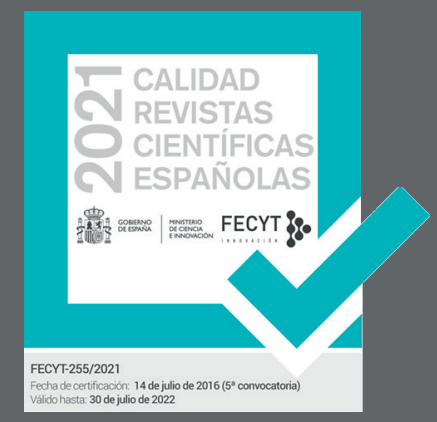




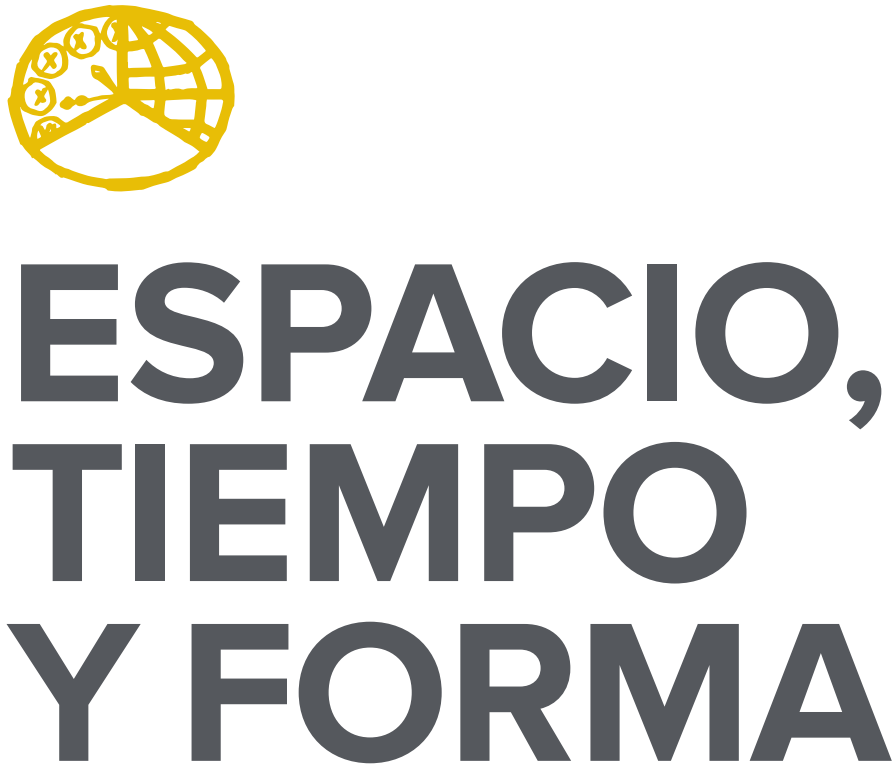

AÑO 2021

ISSN 1131-768X

E-ISSN 2340-1400

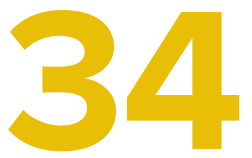

SERIE IV HISTORIA MODERNA

REVISTA DE LA FACULTAD DE GEOGRAFÍA E HISTORIA

DOI: https://doi.org/10.5944/etfiv.34.2021

\section{UกED}

UNIVERSIDAD NACIONAL DE EDUCACIÓN A DISTANCIA 
La revista Espacio, Tiempo y Forma (siglas recomendadas: ETF), de la Facultad de Geografía e Historia de la UNED, que inició su publicación el año 1988, está organizada de la siguiente forma:

$$
\begin{aligned}
& \text { SERIE I - Prehistoria y Arqueología } \\
& \text { SERIE II - Historia Antigua } \\
& \text { SERIE III - Historia Medieval } \\
& \text { SERIE IV - Historia Moderna } \\
& \text { SERIE V - Historia Contemporánea } \\
& \text { SERIE VI - Geografía } \\
& \text { SERIE VII - Historia del Arte }
\end{aligned}
$$

Excepcionalmente, algunos volúmenes del año 1988 atienden a la siguiente numeración:

$$
\begin{aligned}
& \mathrm{N} .^{\circ} 1 \text { - Historia Contemporánea } \\
& \mathrm{N}^{\circ} 2 \text { - Historia del Arte } \\
& \mathrm{N} .^{\circ} 3 \text { - Geografía } \\
& \mathrm{N} .^{\circ} 4 \text { - Historia Moderna }
\end{aligned}
$$

ETF no se solidariza necesariamente con las opiniones expresadas por los autores.

\author{
UNIVERSIDAD NACIONAL DE EDUCACIÓN A DISTANCIA \\ Madrid, 2021 \\ SERIE IV · HISTORIA MODERNA N. ${ }^{\circ} 34,2021$ \\ ISSN $1131-768 X \cdot$ E-ISSN 2340-1400 \\ DEPÓSITO LEGAL \\ M-21.037-1988 \\ URL \\ ETF IV · HISTORIA MODERNA · http://revistas.uned.es/index.php/ETFIV \\ DISEÑO Y COMPOSICIÓN \\ Carmen Chincoa Gallardo · http://www.laurisilva.net/cch \\ Impreso en España · Printed in Spain
}

(c) (7) (8) Esta obra está bajo una licencia Creative Commons Reconocimiento-NoComercial 4.0 Internacional. 


\section{MISCELÁNEA • MISCELLANY}





\title{
LA INFLUENCIA DEL CORSO BERBERISCO EN LA TARDÍA REPOBLACIÓN DEL ÁREA LITORAL DEL REINO DE MURCIA (SIGLOS XVI Y XVII)
}

\author{
THE INFLUENCE OF THE BERBER CORSICAN \\ ON THE LATE REPOPULATION OF THE \\ COASTAL AREA OF THE KINGDOM OF \\ MURCIA (XVI AND XVII CENTURIES)
}

\author{
Francisco Velasco Hernández ${ }^{1}$ \\ Recibido: 13/05/2021 - Aceptado: 24/07/2021 \\ DOI: https://doi.org/10.5944/etfiv.34.2021.27250
}

\begin{abstract}
Resumen
Aunque es un tópico simple y muy recurrido, se suele identificar al corso magrebí como una de las causas que frenó la repoblación de las zonas litorales españolas, sin que apenas haya sido demostrada esta afirmación sobre el terreno y con ejemplos válidos. Con este artículo pretendo probar cómo su incidencia fue especialmente nociva para los habitantes del litoral del reino de Murcia, situado a poco más de un día de navegación de Argel, los cuales apenas pudieron acercarse a la costa durante más de un siglo. La base documental sobre la que me he apoyado abarca varios archivos, como el de Simancas, Histórico Nacional y los municipales de Murcia, Cartagena, Lorca y Mazarrón, contrastada con la bibliografía especializada sobre el tema.
\end{abstract}

Palabras clave

Corsarios berberiscos; repoblación de la costa del reino de Murcia; sureste español; siglos XVI y XVII

\begin{abstract}
Although it is a simple and widely used topic, the Maghreb Corsican is often identified as one of the causes that slowed down the repopulation of the Spanish coastal areas, with little proof of this on the ground and with valid examples. With this article I intend to prove how its incidence was especially harmful for

1. UNED, Centro asociado de Cartagena; francisco.velasco@murciaeduca.es

Archivo General de Simancas [A.G.S.]. Archivo Municipal de Cartagena [A.M.C.]. Archivo Municipal de Vera [A.M.V.]. Archivo Municipal de Murcia [A.M.M.]. Biblioteca Nacional [B.N.]. Archivo Histórico Nacional [A.H.N.]. Archivo Municipal de Lorca [A.M.L.]. Archivo Municipal de Mazarrón [A.M.Mz.].
\end{abstract}


the inhabitants of the coast of the kingdom of Murcia, located just over a day's sailing from Algiers, which could barely approach the coast for over a century. The documentary base on which I have relied covers several archives, such as Simancas, Histórico Nacional and the municipal archives of Murcia, Cartagena, Lorca y Mazarrón, contrasted with the specialized bibliography on the subject.

\section{Keywords}

Berber corsairs; repopulation of the coast of the kingdom of Murcia; southeastern Spain; XVI and XVII centuries 


\section{INTRODUCCIÓN}

La expansión del corso norteafricano con la llegada de los hermanos Barbarroja a Argel en 1516 creó importantes desiertos demográficos en las áreas litorales del Mediterráneo ibérico. Uno de ellos era la costa del reino de Murcia, donde solo consiguieron mantenerse la ciudad de Cartagena y la pequeña villa minera de Mazarrón. Pero otras zonas de su frente marítimo permanecieron despobladas, como es el caso de los campos de Lorca y Mazarrón, el poniente cartagenero y la comarca del Mar Menor.

A diferencia de los reinos de Granada y Valencia, con una buena cobertura a base de torres vigías de herencia medieval y un sistema más o menos eficaz de tropas móviles (milicias concejiles, atajadores a caballo, requeridores), el de Murcia estaba totalmente desguarnecido y a merced de las incursiones corsarias. Solo a mediados del siglo XVI surgió un verdadero interés por dotar a su litoral de la protección necesaria, con la erección de algunas torres defensivas y de vigía, la organización de los vecinos en milicias y cuadrillas y una precaria red de atalayeros en las cimas más elevadas del litoral.

Pero a pesar de estos pequeños progresos, no fue hasta que comenzó a aflojar la presión corsaria cuando los vecinos se atrevieron a instalarse realmente en los parajes próximos a la costa. Fue un proceso de altibajos, con avances y retrocesos, que no se consolidó de forma definitiva hasta bien avanzado el siglo XVII. Esta correlación de hechos, marcada por el ascenso y descenso de la predación berberisca en los primeros siglos de la Modernidad y la ocupación progresiva, aunque lenta en el tiempo, de algunas áreas del litoral, hasta entonces deshabitadas, forman el eje central de este artículo y explican por qué fracasaron con anterioridad los intentos de asentar una población estable en las marinas del reino de Murcia.

\section{UN ESPACIO LITORAL CASI VACÍO EN EL TRÁNSITO DE LA EDAD MEDIA A LA MODERNA}

Tras la ocupación y conquista castellana del reino de Murcia entre I243 y I245 y, sobre todo, con la fracasada revuelta mudéjar de I264, el litoral murciano quedo prácticamente deshabitado, al emigrar casi toda la población musulmana a Granada o al norte de África. Las alquerías próximas al mar quedaron abandonadas y solo se mantuvieron algunos núcleos urbanos fuertemente amurallados en el reino, tanto en el interior (Murcia, Lorca, Mula) como en la costa (Cartagena) ${ }^{2}$.

La situación periférica del territorio murciano y su localización entre dos reinos, Aragón y Granada, normalmente hostiles a Castilla, creó, en palabras de Guy Lemeunier, una hipoteca militar que se mantuvo inquebrantable hasta finales del siglo XV y fue responsable en gran parte del vacío demográfico de este espacio

2. ROdRíGUEZ LLOPIS, 1999: 67-75. 
peninsular 3 . De ese modo, el escaso número de pobladores cristianos, la incidencia de las epidemias de peste y especialmente el daño producido por las constantes razias granadinas fueron motivos suficientes para impedir cualquier intento de ocupación del frente marítimo.

A comienzos de la Edad Moderna -y durante todo el siglo XVI- la población de este reino se localizaba preferentemente en el área septentrional y en la vega media del río Segura. Las comarcas del noroeste, el sector montañoso noroccidental y el partido de Segura abarcaban más del $40 \%$ de los habitantes, mientras que Murcia y su huerta, la vega del río Mula y el Altiplano aglutinaban un 31 \%. Por el contrario, Cartagena con su campo, incluyendo a Mazarrón, apenas rebasaba el $5 \% 4$.

La amplia fachada litoral del reino había quedado repartida desde la conquista cristiana entre los concejos de Murcia, Cartagena y Lorca, siendo esta última la que gozaba de un mayor tramo de costa (I2 leguas). Desde el reinado de los Reyes Católicos, e incluso antes, uno de estos concejos, el murciano, comenzó a entregar tierras en la parte del campo de Cartagena correspondiente a su término municipal. Los nuevos campesinos se fueron asentando en torno a las cañadas, a las ramblas, a los charcos, a los pozos y los aljibes. Sin embargo, como señala Ángel Luis Molina, hasta I474 muy raras veces las concesiones de tierras se localizaron en lugares alejados de Murcia capital 20 o 25 kilómetros, y siempre junto a los caminos que comunicaban con Cartagena y el litoral 5 . Pero será después de finalizada la guerra de Granada en I492, y una vez desaparecido el peligro de las incursiones nazaríes, cuando las donaciones se multipliquen y favorezcan una tímida aproximación a la costa (Cabezo Gordo, Pozo Aledo, Jimenado o Roda).

En el área del campo de Cartagena correspondiente al municipio de la ciudad portuaria, aunque algo más tarde, también se concedieron propiedades en algunos lugares concretos gracias al impulso de la trashumancia de ganados mesteños, que precisaban de zonas de pasto acotadas en dehesas y ejidos. Surgen así en la primera mitad del siglo XVI y en torno a fuentes, pozos, ramblas o palmerales pequeños asentamientos, como Fuente Álamo, Pozo Estrecho, Pozo Alcaide, La Palma, Moncada, El Carmolí, Roche, Las Piquetas, La Aljorra, El Albujón, Hoya Morena, El Garbanzal y Torre Bermeja ${ }^{6}$.

En la marina de Lorca, con una doble frontera, interior y exterior, la posibilidad de asentar población era harto complicada, pues estaba mucho más amenazada y expuesta. Dejando aparte el núcleo minero de Alumbres de Almazarrón, con una evolución diferente, el resto del litoral lorquino constituía un enorme desierto costero. Con todo, hubo intentos de establecer un pequeño núcleo en Águilas, con propuesta de construcción de una torre, pero fracasaron. De hecho, en I50 se solicitó la erección de dos fortines, uno en Águilas y otro en Almazarrón, y solo en este último caso se pudo llevar a cabo la obra de forma definitiva7.

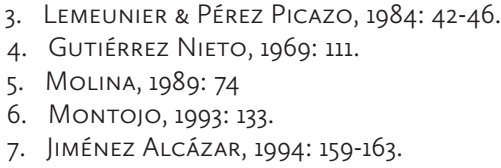


Los pequeños núcleos urbanos de Cartagena y Mazarrón representaban una excepción dentro del amplio tramo costero del reino de Murcia, pues en ellos si se consolidó una población estable que irá creciendo a lo largo de la Edad Moderna, sobre todo en el caso de Cartagena. Esta ciudad levantina, que había perdido su esplendor romano, fue revitalizada de nuevo en tiempos de Alfonso X el Sabio y logró mantener un reducido núcleo de vecinos protegidos por su muralla y castillo, que se ocupaban en actividades relacionadas con la pesca, el comercio y el corso. La reorientación de la política exterior castellana hacia el Mediterráneo a comienzos del XVI facilitó su recuperación como puerto vital para la Corona y muchas de las expediciones militares a Italia y al norte de África tuvieron como punto de partida su privilegiada ensenada. Desde entonces Cartagena no dejó de crecer y se convirtió en uno de los principales baluartes defensivos de la España mediterránea. De forma paralela avanzaron todos sus sectores económicos, se multiplicó su población y asumió su impronta militar ${ }^{8}$. A finales del siglo XVI ya contaba con más de 5.000 habitantes y una próspera actividad comercial .

El núcleo de Mazarrón surgió de la nada gracias al descubrimiento de alumbres en sus inmediaciones. En I462 el rey Enrique IV concedió a Juan Pacheco, marqués de Villena, las minas de este tipo situadas en el reino de Murcia. Villena no tardó en repartir la citada merced con el adelantado Pedro Fajardo y ambos suscribieron en I480 un primer contrato de explotación con el mercader genovés Baltasar Rey y sus hermanos. Cuatro años más tarde ya llegaban barcos procedentes de Mazarrón a la Exclusa, el antepuerto de Brujas ${ }^{\mathrm{I}}$. La explotación inmediata del alumbre atrajo una corriente migratoria que sirvió para consolidar tres pequeños núcleos (Casas Viejas, Casas de la Rambla y Casas Mayores), cuya población alcanzaba en 1526 los I6o vecinos (unos 700 habitantes). Desde entonces, y hasta que se concretó el declive de las minas a finales de ese siglo, el alumbre constituyó un poderoso motor de crecimiento para esta aldea, que llegó a convertirse en villa en 1572 al segregarse del término de Lorca ${ }^{\text {II }}$. En su momento de máximo esplendor llegó a contar con unos 359 vecinos (I59I)

\section{LA EXPANSIÓN DEL CORSO BERBERISCO EN EL SIGLO XVI Y EL FRACASO DE LA REPOBLACIÓN DEL LITORAL MURCIANO}

La agresión del litoral murciano por parte de los corsarios norteafricanos hunde sus raíces en las últimas décadas del siglo $\mathrm{XV}$ y se dio a la par del hostigamiento que de forma sistemática llevaban a cabo los barcos del reino nazarí desde mucho tiempo antes. Pero fue con la irrupción de los hermanos Barbarroja en Argel y sus

\footnotetext{
8. MONTOJO, 1987. 1993.

9. Torres SÁnchez, 1998: 39-40. Velasco, 2001.

10. Ruiz Martín, 2005. Franco Silva, 1996.

11. GUILLÉN, 2001.

12. A.G.S. Cont. Grles., leg $^{\circ} 2.970$, fol. 215 y ss.
} 
aliados turcos cuando los desembarcos y saqueos en la costa se convirtieron en una pesadilla permanente.

Ya I5I9 el concejo de Cartagena alertaba al rey sobre la envergadura de estos nuevos enemigos turcos «tan poderosos y de gente tan valiente y de tanta yndustria en la guerra» que, al unirse a los moros de África, «con quien tienen mucha ynteligençia y amistad..., se a doblado el peligro» ${ }^{13}$. Un año antes estos turcos habían llevado a cabo el terrible saqueo del pueblo de Rojales, a unos 35 kilómetros del límite con Murcia, y en él habían apresado a cincuenta y siete personas, además de profanar e incendiar la iglesia y asaltar muchas casas ${ }^{14}$. Pero tan solo dos años más tarde, en I520, y al sur de la frontera murciana, se produjeron también los asaltos de Mojácar, Vera y Alumbres de Rodalquilar. En el caso de este último fueron capturados sesenta mineros y en el de Mojácar setenta almas, además de otras personas que resultaron muertas ${ }^{15}$.

En estos años el corso berberisco multiplicó sus acciones de forma espectacular y pocas localidades del Mediterráneo ibérico pudieron escapar de sus garras, desde Andalucía a Cataluña o de las Islas Baleares a Valencia. Pero fueron las áreas más próximas a las costas de Berbería, como las del sureste español (a poco más de un día de navegación) las que sufrieron con más intensidad la presión de los marinos de la media luna. De hecho, nadie se atrevía a vivir en la costa y solo algunos núcleos medianamente fortificados, como Almería, Mojácar, Vera, Mazarrón, Cartagena, Santa Pola, Alicante, Villajoyosa o Calpe, consiguieron mantener una reducida población ${ }^{16}$.

Cartagena, por ejemplo, declaraba en el censo de población de I533 que sus vecinos estaban arruinados de tanto pagar rescates, pero también Lorca, que en ese mismo censo señalaba haber perdido más de 200 vecinos en los últimos siete años ${ }^{17}$. Y es que la ofensiva corsaria se mostraba imparable y en constante aumento, como lo demuestran las incursiones llevadas a cabo durante estas décadas en las marinas de Lorca (I5I4, I523, I529 y I538), Mazarrón (I494, I532 y I539) y Cartagena $\left(\mathrm{I} 528, \mathrm{I} 533, \mathrm{I} 538, \mathrm{I} 54 \mathrm{I}, \mathrm{I} 542\right.$ y I547) ${ }^{\mathrm{I}}$. En el siguiente cuadro exponemos una muestra de los principales desembarcos corsarios y razias acaecidos a lo largo del siglo XVI, desembarcos que llegaron a su clímax coincidiendo con lo que Fernand Braudel denominó «segunda edad de oro de Argel», que se inició después del levantamiento de las Alpujarras granadinas y de Lepanto y se prolongó hasta las primeras décadas del siglo XVII.

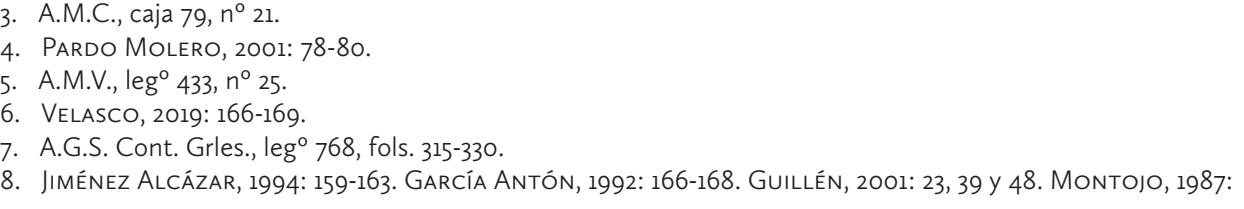


DESEMBARCOS Y RAZIAS EN LITORAL MURCIANO (SIGLO XVI)

\begin{tabular}{|c|c|c|c|}
\hline Fecha & Lugar desembarco & Num. naves & Personas capturadas \\
\hline $09-1505$ & San Ginés de la Jara & Varias galeotas & 5 cautivos \\
\hline $02-1528$ & Campo Cartagena & & Varios campesinos \\
\hline $08-1528$ & Campo Nubla (Cartagena) & 6 fustas & Importantes daños \\
\hline $07-1532$ & Mazarrón & & 2 guardas \\
\hline $01-1533$ & Campo de Cartagena & 24 fustas & 8 \\
\hline $07-1538$ & Campo de Cartagena & & Importantes daños \\
\hline $08-1539$ & Mazarrón & 23 galeotas & Saqueo del pueblo \\
\hline $03-1541$ & San Ginés (Cartagena) & & 2 cautivos \\
\hline $06-1542$ & Cartagena & & Desembarco y grandes daños \\
\hline $11-1547$ & Cartagena & & 13 cautivos \\
\hline $02-1555$ & Cabo Roig/S. Pedro Pinatar & & 4 defensores y 2 trajineros \\
\hline $06-1558$ & Alumbres Nuevos & 8 galeotas & Saqueo del pueblo \\
\hline $04-1561$ & Cartagena & 26 galeotas & Ataque fallido \\
\hline $07-1571$ & Campo de Lorca & & 5 cristianos muertos, 1 preso \\
\hline $10-1573$ & La Manga & & Varios vecinos y alcalde mayor \\
\hline $02-1581$ & Mazarrón & I bergantín & 5 cristianos. \\
\hline $05-1582$ & Cope/Águilas & & 2 soldados de las torres \\
\hline $02-1584$ & Calblanque (Cartagena) & 6 galeotas & «Cautivaron muchos vecinos» \\
\hline $08-1585$ & El Puntarrón (Lorca) & & Varios cautivos \\
\hline $11-1585$ & Camino Lorca-Huércal & & Varios cautivos \\
\hline $03-1586$ & Águilas & 3 galeotas & 3 personas \\
\hline $07-1586$ & Camino Lorca-Huércal & & 7 personas ( 1 escapó) \\
\hline $01-1587$ & Portmán (Cartagena) & 1 galeota & 8 vecinos \\
\hline $02-1587$ & Campo de Cartagena & & Varias personas \\
\hline $07-1587$ & El Pinatar (Murcia) & & 6 pastores \\
\hline $10-1587$ & Campo de Cartagena & 8 galeotas & 8 personas \\
\hline $01-1588$ & Susaña (Mazarrón) & & 15 pescadores \\
\hline $02-1588$ & Cabo Tiñoso/R. S. Ginés & & 2 guardas y varios pastores \\
\hline $01-1589$ & Rincón de San Ginés & & Varias personas \\
\hline $03-1590$ & Cerca de Cartagena & 6 galeotas & 8 hombres \\
\hline $04-1590$ & Rincón de San Ginés & 3 galeotas & 2 hombres \\
\hline $08-1591$ & Cerca puerto de Cartagena & & 1 guarda y 3 pescadores \\
\hline $09-1596$ & Palazuelos (Mazarrón) & 2 galeotas & Fue repelido \\
\hline $06-1598$ & Mazarrón & 4 galeotas & \\
\hline $11-1598$ & Rincón de San Ginés & 1 galeota & 4 pastores \\
\hline $02-1599$ & Portús (Cartagena) & 1 bergantín & 3 pescadores \\
\hline 04-1599 & Cabo Tiñoso & & 2 guardas y 1 familia y criados \\
\hline $11-1600$ & Campo de Cartagena & 5 galeotas & Varios vecinos \\
\hline $12-1600$ & Cabo Tiñoso & 5 galeotas & 3 agricultores y 4 pescadores \\
\hline
\end{tabular}

FUENTES: Archivo General de Simancas (G. y M.) y municipales de Cartagena, Murcia, Lorca y Mazarrón 
Una ofensiva tan brutal como la que recogen estos datos tuvo su reflejo directo en el fracaso de la repoblación de las marinas murcianas, que se mantuvieron como desiertos costeros a lo largo de este siglo. Hubo más de un intento de asentar pobladores en lugares cercanos al mar, pero todos ellos fracasaron. En Lorca, por ejemplo, se intentaron recuperar algunas antiguas alquerías de origen musulmán como Tebar, Aguaderas e Ifre. En I513, Juan de Zafra tenía tomada a censo esta última, pero, ante la imposibilidad de cultivarla por el constante peligro berberisco, la traspasó al genovés Bezón a cambio de que le pagase el dinero necesario para rescatar a sus hijos, cautivos en África ${ }^{\mathrm{I}}$. A mediados de siglo, el regidor lorquino Luis Ponce de León solicitó al rey que se repoblara la costa en aquellos lugares que en otros tiempos fueron asentamientos con castillos y que en esa fecha permanecían derribados. Entre los parajes citados se incluía a Ugéjar, Amir, Chuecos, Tebar, Pulpí y los antiguos puertos de Almazarrón, Cope, Fraile y El Águila. El rey pidió un informe al corregidor el 20 de agosto de 1562 , que debió de resultar negativo, puesto que ya nunca más se volvió a hablar del asunto ${ }^{20}$. Pero la realidad se imponía: el citado informe hacía constar que las doce leguas de costa de mar pertenecientes al municipio estaban totalmente despobladas y que tanto los tres o cuatro puertos situados en el término concejil, cuyos muelles fueron antiguamente utilizados, como las alquerías con torres y castillos ya derruidos y ubicadas a cuatro o cinco leguas de la costa, estaban abandonadas de gente por el peligro de los moros de África ${ }^{21}$.

En la marina perteneciente a la ciudad de Murcia ocurría algo similar, aunque las tierras disponibles fueran de mejor calidad. Aquí se produjo cierto acaparamiento por parte del patriciado urbano, sobre todo por miembros de la oligarquía municipal, que consiguieron importantes donadíos en la parte norte del campo de Cartagena. Pero una cosa eran los repartos de tierras en el área más o menos cercana al litoral, pensados con perspectiva de futuro para el linaje familiar, y otra bien distinta habitar de forma permanente en ella. Por eso, aunque se concedieron algunos donadíos entre 1519 y 1595 en la zona ribereña, especialmente en el Cabezo Gordo (33 parcelas), Los Alcázares (20), Pozo del Ramí (I2), la cañada de La Calavera (Io) y El Pinatar (4), la ocupación efectiva del territorio no se logrará hasta más tarde, ya bien entrado el siglo XVII ${ }^{22}$. La avanzadilla en este sentido pudo estar en torno a un pequeño macizo, el Cabezo Gordo, situado a unos io kilómetros de la orilla del mar, orilla que estaba completamente abandonada a su suerte.

En la marina de Cartagena se producía también una excepción: la del pequeño poblado de Alumbres Nuevos, situado a algo más de una legua de la ciudad y a una distancia similar de la costa. Al igual que Mazarrón, los Alumbres de Cartagena eran de los pocos núcleos habitados relativamente cercanos a la orilla del mar. Había surgido, como aquél, a partir del descubrimiento de alumbres blancos en I525 (diferentes a los rojos de Mazarrón) y acabó siendo explotado por el secretario de Carlos V, Francisco de los Cobos, a quien le fue concedido por juro de heredad.

\footnotetext{
19. Jiménez Alcázar, 1994: 160.

20. García ANTÓn, 1992: 169.

21. Guerrero Arjona, 2005: 288

22. JIMÉNEZ DE GREGORIO, 1984: 94-95.
} 
Hacia 156r se encontraba en plena actividad productiva (unos 6.0oo quintales al año) y ocupaba a más de veinte vecinos ${ }^{23}$. Precisamente por su cierto aislamiento y lejanía de Cartagena sería objetivo recurrente de los corsarios desembarcados en algún punto de la costa.

También en el término cartagenero, como en el de Lorca o en el de Murcia, la lejanía de la costa era la mejor defensa contra los temidos desembarcos corsarios. Es por ello por lo que los primeros núcleos en albergar población estable se situaron a más de doce kilómetros de la orilla del mar. Fuente Álamo constituye en este sentido el mejor ejemplo, pues llegó a desarrollar una importante agricultura de secano (cereales, viñedo, barrilla, olivos y frutales) aprovechando las aguas intermitentes de su rambla, de tal suerte que hacia I59I contaba ya con II2 vecinos ${ }^{24}$. Algo similar ocurrió con otros parajes, como Pozo Estrecho, La Palma o La Aljorra, que también consiguieron arraigar una población estable, aunque menos numerosa que la de Fuente Álamo.

Pero otra cosa bien diferente era el espacio cercano al mar. El peligro aquí era real y muchos campesinos, pastores, leñadores o pescadores cautivos en Berbería pudieron dar buena cuenta del riesgo que conllevaba aproximarse a la costa. Con todo, el afán por conseguir tierras en propiedad llevó a muchos vecinos a solicitar concesiones en lugares demasiado expuestos dada su cercanía al mar. En 1567 el concejo de Cartagena prohibió entregar nuevas heredades más allá del cabezo de Los Mingotes, pues se estaba produciendo un acaparamiento del agro disponible en el Rincón de San Ginés, donde desembarcaban muchos navíos y «cautivan mucha gente y los llevan a Argel $»^{25}$. El 2 de febrero de 1584 seis galeotas pusieron 300 soldados en tierra en Calblanque (cerca de Cabo de Palos) y corrieron el campo hasta llegar a las proximidades de Alumbres, capturando a muchos vecinos de esa parte. Pero mucho más peligrosa fue la incursión llevada a cabo por los jenízaros de Morato Arráez en octubre de 1587 al desembarcar 500 hombres en Portmán, que se enfrentaron en diferentes duelos y escaramuzas a las milicias de Cartagena y Murcia durante tres días, con un saldo de varios corsarios muertos, cinco detenidos y ocho o diez cristianos capturados ${ }^{26}$.

Algunos de estos vecinos apresados, como también otros forasteros, eran pastores. La riqueza de los pastos de los campos de Cartagena y Lorca era bien conocida, siendo puntos terminales de la cañada que conducía a los rebaños de la cabaña conquense. En el municipio cartagenero, por ejemplo, existían varias dehesas cercanas a la ciudad (Mayor, Campo Nubla, Escombreras, Borricén, Roldán), pero también se vendían las hierbas de lugares más cercanos a la costa, como el Rincón de San Ginés. Murcia hacía lo propio con una dehesa que tenía amojonada desde I498 en las inmediaciones de su marina.

Precisamente, en julio de 1587 , fueron apresados seis pastores en El Pinatar cuando guardaban el ganado de Gaspar de Henao, vecino de Murcia, que pidió a su

23. Ruiz Martín, 2005: 188. Franco Silva, 1996: 109.

24. Gutiérrez Nieto, (1969): 114

25. A.M.C. Ac. Cap. 23/11/1566.

26. GRANDAL, (1996/1997). 
ayuntamiento licencia para celebrar una corrida de toros con la que obtener fondos para poderlos redimir de su cautiverio en Argel ${ }^{27}$. Unos meses antes, en febrero, dos galeotas corsarias habían desembarcado su infantería en Calblanque y habían capturado varios pastores y agricultores en la zona de San Ginés de la Jara. En marzo de 1590, seis galeotas de Mami Arráez desembarcaron en Portmán, cautivaron a seis pastores y se llevaron 200 cabezas de ganado ${ }^{28}$. Pero este goteo se mantuvo en los años siguientes, tal como podemos ver en las redenciones hechas por los padres trinitarios y mercedarios en Argel y Tetuán: Juan Valero (1564), Domingo de Murcia (1565), Lorenzo Sánchez (I569), Juan Rodríguez (I570) ${ }^{29}$, Ginés Conesa (I58I) y Juan Martínez (1583) ${ }^{30}$. En 1587 fueron capturados dos manchegos de Cogolludo y Lugar Nuevo cuando guardaban vacas en El Pinatar y un cartagenero de 50 años en el Rincón de San Ginés ${ }^{31}$.

Pero los más perjudicados por la depredación corsaria fueron, sin duda, los pescadores, sobre todo los de Cartagena y Mazarrón. Eran aprehendidos con mucha facilidad en su navegación hacia el cabo de Palos o en la pesca del mújol en las golas de La Manga. En octubre de 1575 fue capturado Juan Herrero, en febrero de 1579 Francisco Fernández y en febrero de 1580 Miguel Abril, pero también Francisco de Medina, natural de Jaén, cuando cargaba pescado en Cabo de Palos en agosto de $1579^{32}$. En enero de 1588 varias galeotas argelinas consiguieron apresar a quince pescadores de la almadraba de Susaña (Mazarrón). En enero de i6or, varios bergantines de moros abordaron unos laudes cerca de Cabo de Palos y se llevaron a cuatro pescadores. Era tal la pérdida de vecinos dedicados a la pesca que el concejo prohibió en 1587 que en adelante se abstuvieran de subir en las barcas a muchachos menores de 18 años, algo similar a lo que se hacía en Andalucía y Canarias³.

\section{SOCORRER A LOS HABITANTES DEL LITORAL: LA ORGANIZACIÓN DE LA DEFENSA MÓVIL (ATAJADORES, ATALAYEROS, MILICIAS Y GALERAS)}

A diferencia de los vecinos reinos de Valencia y Andalucía, el de Murcia no contaba con un sistema permanente de atajadores y requeridores y estaba limitado a la labor de vigilancia y descubierta realizada por algunos lugareños en los promontorios más estratégicos de la costa. En Cartagena, el número de estos vecinos, llamados "guardas de la costa», era de unos treinta a mediados del siglo XVI y se organizaban en grupos de dos o tres en cada una de las estancias. Dos «sobreguardas» a caballo se encargaban de coordinarlos y visitarlos, y de llevar los avisos al concejo y a las

27. A.M.M., Ac. Cap. 7/07/1587.

28. A.G.S., G. y M. leg. $282, n^{\circ} 268$.

29. B.N., Madrid, ms. 2.963

30. A.H.N., códice 119.

31. A.H.N., códice 122.

32. A.H.N., códices 119, 120, 122

33. Velasco, 2019: 111. Anaya Hernández, 2006: 157. Feijoo, 2003: 301-302. 
autoridades militares. El número de estancias o atalayas costeras era normalmente de ocho, pero podía aumentarse en los casos de mayor peligro.

En cuanto a Mazarrón, la villa poseía un sistema de guardas de la costa y atajadores similar al de Cartagena. Fue un sistema impuesto por el rey a los marqueses de Vélez y Villena como condición para concederles la explotación de los alumbres. Por ello debían comprometerse a su mantenimiento y a pagar el sueldo a sus guardianes. Pero este sistema era muy caro y eso provocaba cierta dejación en el compromiso de los marqueses, que no ponían las guardas necesarias o limitaban las estancias a la mínima expresión. En teoría, cada una de estas estancias debía estar ocupada por tres guardas. El número completo de estancias era de catorce, pero rara vez estaban todas operativas ${ }^{34}$. Por lo que se refiere a Lorca, la defensa de su marina era aún más precaria y se limitaba a una torre, la de Cope, con su alcaide y dos o tres guardas, y la puesta temporal de algunas atalayas cerca de las almadrabas, pagadas por los propios pescadores.

El sistema defensivo móvil se completaba con las milicias concejiles armadas. Milicias que no dudaban en embarcarse, si la lucha se ofrecía en el mar, o en recorrer a pie o a caballo la línea de costa de su demarcación para rechazar los desembarcos y las incursiones. En el caso de Cartagena, la milicia estuvo organizado hasta 1550 en siete cuadrillas, compuestas cada una por un número de hombres que oscilaba entre 65 y I30. Después se agruparon en tres compañías, mandadas por un capitán designado por el concejo. Hacia I6I5 eran ya cuatro las compañías y el total de efectivos ascendía a I.I65 soldados, a razón de 29I por compañía. Después, avanzado el siglo XVII, se incorporaron otras compañías del campo, como las de Fuente Álamo, Alumbres y Pozo Estrecho-La Palma. Un papel destacado lo tuvieron también las compañías de caballos, tanto la de Cartagena como la de Mazarrón, pues su mayor celeridad las hacía más operativas a la hora de acudir a repeler los desembarcos corsarios. Se fueron desplegando a mitad de la centuria del XVIl y fueron elemento importante para favorecer el establecimiento de los nuevos pobladores.

A finales del siglo XVI se fue estableciendo la milicia general en Castilla y, del mismo modo, en el territorio correspondiente al reino de Murcia ${ }^{35}$. Pero en algunas poblaciones de su litoral, como Cartagena y Mazarrón, se generó una fuerte oposición a ceder vecinos armados, puesto que ello podía reducir su propia capacidad de autodefensa. De todas formas, ya los años de I620-I630, la milicia territorial del reino de Murcia había quedado perfilada con trece compañías y I.4I5 hombres. La capital aportaba dos compañías y trescientos soldados; Lorca, una compañía y 195 hombres; Mula, I65; Caravaca, I32; y Cartagena, que al final tuvo que ceder, cien ${ }^{36}$.

En los momentos de máximo peligro, cuando eran divisadas poderosas armadas en la costa, se llevaron a cabo socorros desde las ciudades y villas del interior. En el reino murciano estaban obligados a aportar socorro las ciudades de Murcia y Lorca, las Nueve Villas, las diecisiete villas de Chinchilla, la ciudad de Villena, los partidos

\footnotetext{
34. VeLASCO (2014): $235-248$

35. RUIZ IBÁÑEZ, (2009): 29.

36. Martínez Ruiz, 2008: 458.
} 
de Villanueva de los Infantes y de Segura y las tierras de las órdenes militares y de señorío, aunque en la práctica los socorros a Cartagena o Mazarrón provenían casi exclusivamente de la capital, de Lorca, de Mula y de las villas de Totana, Alhama, Aledo y Librilla. Fueron muy continuados los socorros de Murcia a Cartagena y de Lorca a Mazarrón. En la primera mitad del siglo XVI se dieron algunos coincidiendo con la presencia en la costa de las escuadras de Barbarroja, Axé Bajá, Salah Rais y Sinán de Esmirna, pero cobraron gran intensidad a partir de la llegada de Dragut, en I550. Desde entonces, raro fue el año que no se produjo uno de estos socorros. Con el cambio de centuria, las ayudas de las milicias de Murcia se prolongaron, al menos, hasta I637, fecha del último gran socorro contra la amenaza berberisca. Lorca auxiliaba fundamentalmente a Mazarrón, pero tampoco era raro que metiera gente en Cartagena, como en el año 1596.

Por último, el sistema preventivo se ayudaba de la presencia puntual de las galeras de España y, en ocasiones, de las de otros estados aliados en la costa murciana. Su principal base en Castilla era el Puerto de Santa María, en Cádiz, pero la enorme presión del corso turco-berberisco sobre los puertos mediterráneos les obligó a permanecer durante largas estancias en Málaga y Cartagena, sobre todo en esta última, donde solía realizar en muchas ocasiones la invernada. La labor de patrulla de estas unidades navales se complementaba con las visitas ocasionales de las otras escuadras de galeras aliadas (Génova, Nápoles, Sicilia, Cerdeña o Malta). Todas ellas realizaban a su paso importantes «limpias» en los mares ibéricos y en el Sureste, en particular.

Qué duda cabe que este sistema disuasorio, aunque precario e incompleto, evitó que se produjeran grandes tragedias humanas en el litoral murciano, toda vez que, salvo los sustos mayores provocados por los asaltos frustrados de Euldj Alí a Cartagena en I56r y de Morato Arráez a Mazarrón en I585, las demás acciones corsarias fueron desembarcos y pequeñas razias que apenas avanzaron hacia el interior.

\section{ASEGURAR LA LÍNEA DE COSTA: LA CONSTRUCCIÓN DE UNA PRECARIA RED DE TORRES DE DEFENSA Y VIGİA}

La intervención directa de la Corona en la defensa del litoral murciano, con la implementación de una red de torres que protegiera su frente marítimo, no se inicia hasta el reinado de Felipe II. Por entonces, las costas del Mediterráneo español sufrían un acoso tremendo del corso berberisco y en algunas zonas muy expuestas, como las Baleares o el reino murciano, la situación era dramática ${ }^{37}$. De ahí que, en la década de 1560 , el rey encargara a Vespasiano Gonzaga y al ingeniero militar Juan Bautista Antonelli la inspección del litoral de Murcia con el fin de seleccionar los lugares más apropiados para instalar en ellos una red de torres costeras de defensa. Los informes de ambos expertos preveían la construcción de 36 torres, desde El Pinatar hasta Punta Almagrera, en la actual provincia de Almería. Una propuesta

37. Seguí Beltrán, (2015). Espino, (2006). 
demasiado ambiciosa y cara que no llegó a cuajar, y que, tras numerosas dilaciones, acabó reduciéndose a la erección de solo cinco torres, esparcidas por todo el frente litoral (Terreros Blancos, Águilas, Mazarrón, La Azohía y Cabo de Palos)38.

Pero antes de la construcción de estas últimas, los concejos de Lorca y Murcia tomaron la iniciativa ante la falta de respuesta por parte de la Monarquía. Lorca levantó en primer lugar la torre del Puerto de Mazarrón y más tarde la de Cope, que no terminó de rematarse hasta 1573. Pero adolecía de un grave defecto y era su errónea ubicación a ras del mar, por lo que era constantemente batida por las naves corsarias y capturados sus alcaides y soldados ${ }^{39}$. Murcia no construyó una torre en su frente marítimo hasta I563, puesto que la de Los Alcázares, al otro lado de la marina, no era sino remodelación del viejo alcázar marítimo de Ibn Mardanis (de finales del siglo XII) ${ }^{40}$. Se trataba de la torre de La Encañizada, en La Manga del Mar Menor, que servía de refugio y almacén a los pescadores.

Las auténticas torres-fortaleza erigidas en la costa fueron las del proyecto Antonelli-Gonzaga, es decir, las de Cabo de Palos, Azohía, Testa de Mazarrón y Águilas, todas con una planta similar (poligonal), hechas en mampuesto muy reforzado, con tres estancias en altura y una terraza en la que se ubicaban las piezas de artillería, armamento y pólvora ${ }^{41}$. Su planta era hexagonal, con puerta de acceso en la primera planta, escalera de caracol interior, dos pisos abovedados y una terraza en la que se ubicaban las piezas de artillería, armamento y pólvora ${ }^{42}$. Sus potentes cañones ejercieron una importante labor disuasoria que evitó más de un desembarco.

Pero lo que más nos interesa aquí es resaltar lo que supusieron su construcción como revulsivo para extender la pesca a los lugares más alejados de litoral murciano. Cartagena, que ya contaba con dos almadrabas antiguas (Escombreras y Celitrona), pudo abrir dos nuevas tras la construcción de las torres de Cabo de Palos y La Azohía, que multiplicaron el número de capturas y su venta en los mercados del resto del reino y de La Mancha. Mazarrón hizo lo mismo en Susaña y Bolnuevo, y Lorca en Cope y Calabardina. Fue algo parecido a lo que ocurrió en otras almadrabas del litoral español, como las del cabo de Gata en Almería o las del duque de Medina Sidonia en Tarifa ${ }^{43}$.

Los beneficios producidos por las dos nuevas almadrabas de Cartagena pronto empezaron a ser considerables. En los primeros seis años después de su construcción, aportaron solo del impuesto de medio real por arroba 2.391.678 maravedís, a una media anual de casi 400.000 maravedís $^{44}$. Y a finales del siglo XVI un informe confirmaba que la venta de su pescado alcazaba ya unos 15.000 ducados al año, dando

\footnotetext{
38. Velasco, (2012): 10-25. Gil Albarracín, 2018.

39. A.G.S., G. y M., Leg ${ }^{\circ} 241, n^{\circ} 235$.

40. Montojo, (2008): 41-64. TORRES Fontes, (1989-1990): 183-188.

41. A.G.S., G. y M., leg. 177, $n^{\circ}$ 28. VELASCO (2012): 10-25.

42. Cámara Muñoz, (1990): 61-63.

43. Guerrero Arjona, 2005: 315-323. Abad Cerdán, (1995-1996): 82-85. Pérez de Colosia \& Sarriá Muñoz, (1991): 241-254.

44. A.G.S., G. y M., leg. $177, n^{\circ} 28$.
} 
ocupación a cerca de 500 pescadores ${ }^{45}$. Pescadores, que solo para la del «retorno» de Cabo de Palos, concurrían en número de trescientos hacia $1647^{46}$.

También Murcia intentó implantar bajo el amparo de la torre de El Estacio una almadraba de atunes, que en los años de 1605 y I606 produjo unas 25.000 arrobas de pescado, pero debió de ser efímera, pues la presión incesante del corso y la dificultad de defenderla la hicieron inviable ${ }^{47}$.

Aunque esta precaria red de torres no era suficiente para frenar la ofensiva corsaria, si es cierto que en muchas ocasiones sirvieron de refugio a pescadores, agricultores y pastores y, con las «casas fuertes de escudo y lanza» de particulares (normalmente pertenecientes a las oligarquías) diseminadas por el área prelitoral, coadyuvaron a fijar determinadas familias en caseríos y aldeas cercanos a la costa.

\section{LA FUERTE PRESIÓN CORSARIA DE LA PRIMERA MITAD DEL SIGLO XVII Y LA LENTA APROXIMACIÓN A LA COSTA}

Como dijimos más arriba, el avance desde el interior hacia la costa fue muy lento, sobre todo en la mayor parte del siglo XVI, tanto por la falta de pobladores como por el fuerte incremento de la presencia corsaria en litoral. Pero, aunque el peligro no desapareció, e incluso aumentó en las primeras décadas del XVII, la mayor presión demográfica y la mejora de la situación defensiva (mayor presencia de galeras del rey en la costa, edificación de nuevas torres y mejor organización de las milicias) animó a muchos a acercarse al frente litoral. Un ejemplo de ello es la construcción de casas-fortaleza en la misma ribera del Mar Menor en las que se amparaban pescadores, pastores o agricultores. Algunas de éstas fueron las del Negro, Doña Lucrecia, Oviedo y Los Cuencas en el término de Cartagena o las de Ramí y Sandoval en el de Murcia ${ }^{48}$.

Precisamente en la transición de los siglos XVI al XVII se cierra definitivamente el peligroso flanco del Mar Menor con la construcción de tres nuevas torres. El proceso se inició con las obras de la torre de El Estacio, en La Manga, en el invierno de I59I. A ella le siguió la de Portmán (Cartagena) que, aunque quedaba situaba fuera del contorno del Mar Menor, eliminó esta peligrosa vía de acceso al Rincón de San Ginés y a la misma laguna por poniente. Fue rematada en el año I597 y como resultado de ello quedó un fortín protegido por dos cañones que impidió los tradicionales desembarcos y estancias de las escuadras corsarias en esa bahía, a la que algunos famosos almirantes de Argel, como Morato Arráez, tenían especial predilección ${ }^{49}$.

La última de todas fue la torre de El Pinatar, cuya construcción se retrasó por falta de fondos y no recibió el impulso definitivo hasta los últimos años del siglo $\mathrm{XVI}$, cuando el virrey de Valencia y la ciudad de Orihuela insistieron ante el rey para

45. A.G.S., G. y M., leg. $511, n^{\circ} 63$

46. A.M.C. Ac. Cap. 19/07/1647.

47. LEMEUNIER, (1987): 227.

48. RUBio PAREDES, 2000: 99-100.

49. Grandal, (1997): 161-175. A.G.S., G. y M. leg. 204, $n^{\circ} 79$, leg. 245, $n^{\circ} 152$ y leg. 282, $n^{\circ} 268$. 
que el concejo de Murcia cumpliera su compromiso anterior ${ }^{50}$. La obra finalizó, con algunos imprevistos, en diciembre de $1603^{51}$. Con ella quedaba cerrado el portillo existente entre los reinos de Murcia y Valencia y se mejoraba la comunicación de los avisos de enemigos entre ambos reinos.

Pero las numerosas incursiones tierra adentro de los corsarios y el daño consiguiente en vidas humanas demostraban la precariedad de este sistema defensivo, en el que las pocas torres construidas en la costa y la ayuda de unas tropas móviles demasiado lentas y poco operativas resultaban insuficientes para proteger a los vecinos instalados en el área litoral. Aunque Cartagena, por ejemplo, contaba a comienzos de esa centuria con cuatro compañías urbanas de milicia, con 29I soldados cada una, a las que se añadieron conforme se ocupaba el campo las de Fuente Álamo, Alumbres y Pozo Estrecho-La Palma, su movilización dejaba mucho que desear, hasta tal punto que cuando llegaban a los lugares de desembarco el enemigo ya se había marchado con antelación. Eran más eficaces, sin embargo, usando tácticas de emboscada en aquellos parajes donde los corsarios solían hacer aguada (Portmán, Las Amoladeras o El Galán) y en más de una ocasión consiguieron capturar a unos cuantos berberiscos, aunque también se dieron casos en los que fueron ellos los sorprendidos, como le ocurrió al alcalde mayor de Cartagena en octubre de 1573, cuando fue detenido en las playas de La Manga junto con otros soldados por los jenízaros de unas galeotas argelinas ${ }^{52}$. Las compañías murcianas y lorquinas eran aún más inoperativas, pues a la importante distancia existente entre el núcleo urbano y su marina (unas siete u ocho leguas), que debían recorrer a pie, se sumaba un sistema de recluta y apercibimiento algo caótico ${ }^{53}$. El ejemplo más gráfico en este sentido sucedió en agosto de I602 cuando una parte de la milicia de Lorca se adelantó para socorrer la torre de Cope y fue sorprendida por los jenízaros de Morato Arráez, que capturaron a 6o soldados, incluyendo a los dos regidores que actuaban de capitanes de la tropa ${ }^{54}$.

Para colmo de males, en la década de i63o fueron destruidas buena parte de las torres levantadas con gran dificultad en el siglo anterior. Ya con anterioridad había sido arrasada y casi demolida la torre de Cope en I6o2 y así permaneció hasta bien avanzada la centuria. Estos ataques y asaltos a las torres de la costa murciana por los corsarios berberiscos fueron una práctica bastante habitual a lo largo de la Edad Moderna, que no difería en mucho de la que realizaron contra las de otros espacios litorales próximos, como los reinos de Valencia o Granada, o mucho más lejanos, como las riberas italianas 55 .

En el verano i635 fue atacada por primera vez la torre de Águilas y sus defensores fueron capturados, pero al verano siguiente desembarcaron de nuevo unos «cuatrocientos turcos de pelea» y la batieron de forma definitiva ${ }^{56}$. El estío de I637 iba ser

50. Requena Amoraga, 2001: 190-193

51. A.M.M. Ac. Cap. 16/12/1603

52. A.M.C. Ac. Cap. 9/10/1573 y caja 99, $n^{\circ} 11$

53. RUIZ IBÁÑ̃EZ, 1995: 84-88.

54. VELASCO, (2011): 83-102

55. Requena Amoraga, 1997. Gil Albarracin, 2004. Fenicia, 2004. Russo, 2009.

56. A.G.S. G. y M., leg ${ }^{\circ}$ 1.147, y A.M.L., Ac. Caps. 30/06/1635 y 16/08/1636. 
peor aún, pues todas las torres del Mar Menor caerían en las garras de los corsarios capitaneados por Alí Bitchín. Así, en apenas dos días, fueron sometidas a un intenso bombardeo desde el mar por seis galeras, que las dejaron tan maltrechas que ya no pudieron recuperarse. Uno a uno, fueron cayendo los baluartes de Cabo de Palos, El Estacio, La Encañizada y Pinatar, a la vez que sus defensores fueron apresados y su artillería robada. La peor parada resultó la de Cabo de Palos, pues no solamente fue ejecutado de forma cruel y al pie de la torre su alcaide, sino que además su edificio quedó desmochado e incendiado, sin cañones ni armas de defensa ${ }^{57}$.

La destrucción de las torres supuso un duro revés para los habitantes de la costa pues quedaron expuestos más que nunca a las incursiones corsarias y perdieron los mejores refugios para protegerse. En octubre de I640 se produjo un peligroso desembarco cerca de Cabo de Palos en el que varias galeras trasvasaron su infantería a tierra y corrieron el campo de Cartagena hasta llegar al convento de San Ginés de la Jara, que fue cruelmente asaltado, con destrucción de sus imágenes de santos y robo de los sagrados ornamentos, además de capturar a diez y ocho personas que se llevaron a $\operatorname{Arge}^{18}$. También en Mazarrón, en junio de I642, un bergantín corsario de I4 bancos persiguió a dos barcas de pesca y las obligó a embarrancar en Los Rafales. Más de veinte corsarios saltaron a tierra a buscar a una decena de pescadores que se habían salvado de milagro. El concejo de esta villa organizó una búsqueda de los corsarios sin éxito, puesto que estos se habían refugiado al amparo de la demolida torre de Cope 59 .

Ante esta situación, los concejos de Murcia, Cartagena y Lorca protestaban airadamente ante el Consejo de Guerra y pedían al rey que se procediera a la rápida reparación de las torres, pues se sentían totalmente desprotegidos. La situación se enquistó en las décadas centrales de ese siglo y apenas se avanzó nada. Mientras tanto, la presión corsaria se mantenía alta, a pesar de los reveses sufridos por los berberiscos en la guerra de Candía y el impacto negativo de la peste africana, que diezmó buena parte de las tripulaciones de sus navíos ${ }^{60}$. El concejo de Cartagena, cuyos vecinos sufrían como nadie los estragos del corso, reforzó la vigilancia en la zona de Cabo de Palos: primero envió un guarda permanente al poco de ser destruida la torre (I637) y posteriormente nombró un gobernador en I643 con la misión de mejorar la defensa de la zona y dar apoyo a los pescadores que utilizaban su almadraba. A la par realizó diversas peticiones y propuestas al rey para recuperar la torre ${ }^{61}$. Murcia también emprendió una importante ofensiva ante el Consejo Real para conseguir que el marqués de los Vélez iniciara la reparación de sus torres. Lo solicitó en octubre de I637, en agosto de I640 y en julio de I645, pero no obtuvo un resultado satisfactorio. Lorca hizo exactamente lo mismo en I643 y i652 y recibió la callada por respuesta ${ }^{62}$.

\footnotetext{
57. RUIZ IBÁÑEZ y MONTOJO, 1998. VelAsco (2015): 179-181.

58. A.M.M. Ac. Cap. 21/10/1640.

59. A.M.Mz., Ac. Caps. 6 y 8/6/1642.

6o. Mesa Coronado, (2014): 83-90. Sebag, 1989: 62-63.

61. A.M.C. AC. Cap. 9/04/1646.

62. García Antón, 1992: 259-260.
} 
A pesar de estas dificultades, el proceso de acercamiento a la costa era ya imparable y muchos nuevos colonos comenzaron a asentarse en la comarca del Mar Menor y en la marina de Mazarrón, aunque no así en la de Lorca. En el término municipal de Cartagena la vanguardia la constituía el monasterio de San Ginés de la Jara, pero a su espalda ya se habían establecido núcleos habitados como Alumbres, El Algar, El Lentiscar o El Garbanzal, a poca distancia de la orilla del mar. El campo cartagenero crecía, a pesar del peligro corsario, y en ya i606 existían unas I.8I3 casas diseminadas por el área rural, lo que supone un $28 \%$ del total ${ }^{63}$. En el término de Murcia habían hecho lo propio Torre Pacheco, La Calavera, Roda, San Cayetano, San Francisco Javier y El Pinatar, en algunos de cuyos lugares se había erigido una ermita, que, en ciertos casos, acabará convirtiéndose en parroquia a finales de esa centuria. En El Pinatar se documenta un asentamiento de siete vecinos en I630, lo que supone un testimonio fehaciente de poblamiento temprano en el litoral, al igual que otros casos como Los Alcázares o La Calavera, caserío este último donde ya existía una ermita en $\mathrm{I}_{640^{64}}$. Precisamente en el área de Los Alcázares se hicieron bastantes mercedes de tierras por el concejo de Murcia entre I54I y i604 (más de 250 pares de labor), concentradas en los parajes Pozo Ramí, Hoya Morena, Pocico de Bezón, Pozo Calatayud, Villares del Gato y El Lentiscar ${ }^{65}$.

La oligarquía murciana civil y eclesiástica también fomentó el asentamiento de colonos en aquellos pagos en los que se les habían concedido extensas propiedades. En el caso de Roda, a poco más de tres kilómetros de la orilla de la laguna, el regidor Pablo de Roda estableció un mayorazgo para su hijo en la concesión de los I8 pares de labor (576 fanegas) que había recibido del concejo. El establecimiento creció rápido y se convirtió en una pequeña aldea en I6I3 «con lo procedido de los frutos de ella, y de su hacienda y caudal propio a edificado y hecho las casas y lo demás comprehendido en la dicha heredad y una balsa questá en ella» ${ }^{66}$. En Torre Pacheco, situado a unos io kilómetros del mar, ocurrió algo parecido: tuvo su origen en una heredad de finales del siglo XV, pero no conoció un importante crecimiento hasta que cayó bajo del patronazgo del deán Luis Pacheco de Arróniz, el cual sobre la base de una vieja ermita consiguió en I603 la erección de la parroquia de Nuestra Señora del Rosario ${ }^{67}$.

Hubo incluso un pequeño señorío, denominado de Hoya Morena y Ramí, que fue establecido a principios del siglo XVII por la familia de regidores cartageneros Bienvengud en las tierras cercanas al Mar Menor, situadas a un lado y otro de la rambla de El Albujón. Se trataba de un minúsculo señorío rodeado por territorios de realengo y que hacia la década de 1620 se articulaba en torno a los caseríos de Villa Morena, Ramí y La Puebla, en los que vivían unos I7 labradores con sus respectivas familias ${ }^{68}$.

\footnotetext{
63. TORRES SÁNCHEZ, 1998: 80.

64. JIMÉNEZ DE GREGORIO, 1984: 133.

65. BUENDÍA PORRAS, 2008: 144-145.

66. Lemeunier \& PÉREZ PICAZO, 1984: 107.

67. Candel CRespo, 1969: 46-49.

68. MONTOJO, (1987-88): 24 .
} 


\section{EL DESCENSO DE LA ACTIVIDAD CORSARIA Y LA REPOBLACIÓN TARDÍA DE LAS MARINAS}

Aún a mediados de siglo las acciones corsarias no cejaban. En la década de i650, una vez dada por concluida la epidemia de peste de I648, las incursiones en la costa volvieron a multiplicarse. En mayo de I650 desembarcaron más de cuarenta soldados de una galeota en el puerto de Cabo de Palos y corrieron el Rincón de San Ginés hasta que fueron expulsados por la compañía de caballos del capitán Francisco Imperial y la de infantería de Los Alumbres. Imperial descendía de una poderosa familia de mercaderes genoveses de Alicante y Cartagena, que se insertaron con éxito en la estructura militar de los Austrias ${ }^{69}$. Pero tres meses después eran dos galeras reales las que pusieron en tierra su gente, también en Cabo de Palos, y avanzaron por esa parte hasta que los frenaron a arcabuzazos las tropas de Cartagena, con las cuales se batieron en duelo ${ }^{70}$. En agosto del año siguiente volvieron a aparecer dos nuevas galeotas en el mismo paraje con la intención de desembarcar, y para ello dispararon previamente seis cañonazos, pero les aguardaban los pescadores armados de la almadraba de Cabo de Palos, reforzados por la compañía de caballos y cincuenta infantes de la compañía de Alumbres, que les disuadieron de hacerlo. En mayo de I652 se descubrieron allí otras dos, en mayo de I653 una y en agosto de i654 otra más. En vista de ello, en diciembre de ese año, el concejo de Cartagena acordaba una vez más pedir al rey y al consejo de guerra que se procediera a la restauración de la torre de Cabo de Palos, pues eran numerosos los apresamientos de vecinos y naves mercantes en esa zona de la costa y muy perjudicial el daño que sufría el comercio de la ciudad. Al final, los pescadores de Cabo de Palos habían aprendido a defenderse por sí solos, aunque con apoyo militar de la ciudad. En agosto de i659, el concejo les autorizó su campaña estival con varias condiciones: cada pescador debía llevar su arma de fuego, pólvora, balas y cuerda, tenían que establecer un cuerpo de guardia y situar centinelas y postas en lugares estratégicos, además de desplazar hacia allí dos cañones encabalgados con sus correspondientes balas ${ }^{71}$.

En el otro extremo del litoral murciano, la ruina de las torres de Cope y Águilas favorecía la actividad de los bergantines corsarios. En junio de i654 fue derrotada la cuadrilla de Vera en el límite con Lorca cuando perseguía a una de esas naves. Los corsarios les habían matado cinco de los cincuenta soldados que la componían y se batían en retirada ${ }^{72}$. Pero en marzo de i657 la milicia de Lorca tuvo cierta compensación cuando, aprovechando una argucia, consiguieron que una reducida tropa berberisca desembarcara en la playa de Águilas y se arcabucearan, con el resultado de varios corsarios muertos y uno de ellos aprehendido ${ }^{73}$.

A pesar de todo, el miedo al corsarismo berberisco iba remitiendo y muchos agricultores cartageneros se atrevían ya a pedir tierras de cultivo en zonas muy

69. RuIz IBÁÑEZ \& Montojo, 1998: 171-175.

70. A.M.C. Ac. Caps. 25/05 y 25/08/1650.

71. A.M.C. Ac. Cap. 9/08/1659.

72. A.M.L. Ac. Cap. 3/06/1654.

73. García Antón, 1992: 186-189. 
cercanas a la ribera del Mar Menor. Zonas marginales y salitrosas donde crecían de forma natural algunas plantas xerófilas, como la sosa, la barrilla y el esparto, muy utilizadas en la industria del jabón, el teñido y confección de ropas o la fabricación de espejos y cristales, y que constituían uno de los pilares más importantes del comercio de exportación de la ciudad. En los años de i689/1690 y i695/1707, por ejemplo, salieron hacia el exterior 9.292 y 195.59 quintales de barrilla respectivamente $^{74}$. En I658, algunos vecinos solicitaron tierras en esta zona: José Rosales, soldado de la compañía de caballos, pidió 25 fanegas de tierra en la falda de Los Mingotes, junto a las que se habían entregado a Carrión, un compañero suyo; lo mismo hizo Juan Carrión Mula, en este caso de 30 fanegas para labrar y un terreno para hacer un corral donde guardar su ganado cabrío; también Juan Díaz de Aragón se le dieron otras 20 fanegas y a otros muchos. Incluso hubo quien las demandó casi a la misma orilla del mar, como las 30 fanegas que se entregaron en la boquera de Calblanque ese mismo año ${ }^{75}$. Todo ello no hacía sino confirmar el progreso en la ocupación del área rural de Cartagena, que ya en los primeros años de la década de 1640 se estimaba en unas cinco o seis mil personas ${ }^{76}$.

Pero, aunque la expansión demográfica era imparable, aún faltaba por resolver el asunto de las torres destruidas en la década de i630. La primera en ser reconstruida fue la de Águilas, en el término de Lorca. A lo largo de I654 este concejo fue recaudando el dinero necesario para repararla e inició la nueva obra hacia noviembre, de tal forma que en marzo del año siguiente fue rematada y se le dotó de los correspondientes soldados y artillería ${ }^{77}$.

Aunque no sabemos la fecha exacta de la restauración de la torre de El Estacio, sabemos por testimonios indirectos que debió hacerse en el invierno-primavera de I662-I663, pues en un escrito de abril de ese último año remitido por el concejo de Cartagena al marqués de los Vélez, éste le trasladaba las quejas de sus vecinos que estaban pagando el mantenimiento de la torre de El Estacio a pesar de que no formaba parte de su jurisdicción ${ }^{78}$.

La reconstrucción de la torre de Cabo de Palos se retrasó una década más con respecto a la anterior. No fue hasta 1674 cuando por iniciativa del gobernador militar de Cartagena, el general de artillería Juan González Salamanquez, se dio el impulso definitivo. Para ello contó con la colaboración del concejo y de muchos de los vecinos del campo, que con sus carros y mulas llevaron gratis numerosas cargas de piedras y cal hasta la torre. La obra debió realizarse a buen ritmo durante el invierno, de tal forma que antes de acabar la primavera ya estaba concluida ${ }^{79}$.

Qué duda cabe que con la reconstrucción de todos estos baluartes mejoró de forma considerable la defensa de la costa y sirvieron de trampolín para la llegada de nuevos pobladores. En la parte correspondiente a la marina de Murcia, la hacienda

74. VelAsCO, (2004): 156.

75. A.M.C. Ac. Caps. 4/05, 11/05 y 1/11/1658

76. TORRES SÁNCHEZ, 1998: 92.

77. A.M.L. Ac. Caps. $24 / 11 / 1654,19 / 01 / 1655,15 / 02 / 1655$ y 13-03/1655.

78. A.M.C. Ac. Cap. $17 / 04 / 1663$

79. A.M.C. Ac. Cap. 3/05/1675. 
de Los Alcázares constituyó la vanguardia en la colonización de la orilla occidental del Mar Menor. Entre i649 y I655 fue ahitada y amojonada su superficie, correspondiente a I2 pares de labor (unas 384 fanegas), con las cuales se suponía debía de vivir holgadamente el alcaide de la torre y su familia, mantener operativo el baluarte y aportar con su arrendamiento el dinero suficiente para el mantenimiento y limpieza de los diez aljibes anexos ${ }^{80}$. Eso era en teoría, pero en la práctica la torre había sido abandonada y casi derruida y algunos labradores del campo habían usurpado buena parte de las tierras de labor en su beneficio ${ }^{81}$. En los actuales municipios de San Javier y San Pedro del Pinatar también se fueron erigiendo algunos caseríos aislados. En la Calavera, por ejemplo, existía en I645 una ermita, la de San Juan, en la que se impartía misa los domingos y asistían a ella no sólo los moradores del contorno sino también los pescadores de La Encañizada ${ }^{82}$.

El crecimiento demográfico de la marina murciana hizo que sus moradores trataran de organizarse en una milicia rural al igual que las que existían en el término de Cartagena. Así, en i663, varios vecinos de esta parte pidieron a su concejo que nombrara cinco cabos para organizar la defensa del territorio ante las agresiones corsarias, uno para La Calavera, otro para La Grajuela, otro para El Pinatar, que se reunirían en la ermita de San Juan, y otros dos, para los partidos de Aledo y Octavio.

En la zona oriental correspondiente a Cartagena la presión sobre los baldíos de esta zona se hizo cada vez mayor en los años anteriores y posteriores a la peste bubónica de i676. En diciembre de I675, el concejo se planteó poner fin al continuo desmonte que llevaban a cabo los vecinos en los terrajes del Rincón de San Ginés y su saladar, considerado un propio de la ciudad. Pero dos años después, en marzo de I677, el problema seguía ahí e incluso se había extendido hasta el espacio de Calblanque y otros baldíos pegados al mar, tanto en la costa de levante como en la de poniente. Y ello se unía la entrada furtiva de ganados a pastar en el citado Rincón que provocaba constantes enfrentamientos con los labradores, aparte de defraudar las rentas del concejo. Además, el enorme agujero financiero que se creó con la epidemia obligó a arrendar deprisa, al mejor postor y al contado muchas de las rentas y propios de la ciudad, como los barrillares de Portmán, San Ginés y Calblanque y otros baldíos pertenecientes al concejo ${ }^{8_{3}}$.

Todos estos hechos no hacen sino confirmar que se había producido, por un lado, una ocupación cada vez mayor de las tierras y lugares próximos al mar, que durante muchas décadas permanecieron yermos y abandonados, y, por otro, que el corsarismo, aunque no había desaparecido del todo, si había menguado bastante. De hecho, los datos disponibles comienzan a hablar por sí solos. Un recuento de vecinos hecho en I683 para establecer un reparto proporcional del nuevo encabezamiento de alcabalas, cientos y millones provocó un tumulto popular que finalmente hizo desistir de su cobro a la oligarquía municipal. Esta asonada del campo de Cartagena y su recuento correspondiente nos confirma que ya se habían consolidado varios

\footnotetext{
80. Buendía Porras, 2008: 156.

81. A.M.M. Ac. Caps. 18/03/1655 y 25/05/1655.

82. JiMÉnEZ de GREGorio, 1984: 134.

83. A.M.C. Ac. Caps. $3 / 12 / 1675,6 / 03 / 1677$ y $23 / 03 / 1677$.
} 
«pagos» en la comarca del Mar Menor y que a escasos cinco kilómetros de su orilla -incluso menos- se habían erigido aldeas en La Calzada, en el pago, loma y pozo de El Algar, en Torre de Cuenca, en Derramadores, La Torreta, Carmolí, Campo Bajo, El Ramí, La Puebla, Pozo Nuevo o el Arquillo, pero en algunos lugares concretos existía un número de moradores interesante. En este sentido, el campo de San Ginés de la Jara, con 35 personas, el Lentiscar, con I36, y el Garbanzal, con I74, constituían las áreas más pobladas ${ }^{84}$.

En la parte correspondiente a Murcia ocurrió algo similar, aunque en este caso no disponemos de un padrón vecinal para poder precisar con mayor detalle el número de habitantes y caseríos existentes. Aquí, como en Cartagena, asistimos a la usurpación de baldíos correspondientes a los propios concejiles murcianos ante la presión de los nuevos pobladores. Un buen ejemplo de ello son los doce pares de labor anexos a la torre de Los Alcázares y las vertientes de sus aljibes, que habían sido roturados por diversos vecinos del campo -algunos de ellos de Cartagena- y que el ayuntamiento se dispuso a recuperar en I685. Después de ahitarse las tierras, se comprobó que su extensión era de I4 pares y I7 fanegas (unas 455 fanegas), con los cuales se estableció una importante hacienda cuyos frutos sirvieron además para costear la limpieza permanente de los aljibes ${ }^{85}$. También las órdenes religiosas se habían aprovechado del reparto de las nuevas tierras de cultivo del área del Mar Menor. El convento de la Santísima Trinidad, por ejemplo, había conseguido que el ayuntamiento de Murcia le concediera doce pares de labor en La Grajuela, con 2,5 leguas de contorno (casi I4 kilómetros), con cuyas tierras llevaba a cabo un gran negocio al venderlas o arrendarlas a determinados campesinos, hecho que fue investigado por el propio concejo ${ }^{86}$.

La marina de Mazarrón, que había quedado muy afectada con el abandono del laboreo del alumbre por parte de los marqueses de los Vélez y Villena a fines del siglo $\mathrm{XVI}$, supo reconvertir su actividad minera con la explotación de otro producto con salida comercial: el almagre. También se volcó en el cultivo de la sosa y la barrilla, en cuyos terrenos salitrosos y de secano se adaptaba con facilidad, e igualmente mantuvo operativos otros sectores más tradicionales como la pesca y las salinas. Fruto de ello fue el avance de algunos caseríos de la marina, caso de Balsicas, Cañada de Gallego, Las Moreras y El Saladillo.

Por lo que se refiere a la marina de Lorca, su repoblación fue la más tardía y escasa y no se concretó hasta finales del siglo XVII y principios del XVIII. A comienzos de ese último siglo, el padre Morote, contemporáneo a los hechos, hablaba de asentamientos en Ifre, Torre Morata, Ramonete, Capezos, Ugejar y Viquejos: «cultivan en este partido sus tierras ochenta vecinos, los que tienen una grande hermita y capellán permanente, y distan del mar una legua con poca diferencia» ${ }^{87}$. Aunque esto no nos debe llevar a engaños: el único núcleo urbano como tal en esta zona, Águilas, no se fundará hasta I765, en tiempos de Carlos Ill.

\footnotetext{
84. Sánchez Belén \& Alcaraz Hernández, (1991): 172-183.

85. BUENDÍA PORRAS, 2008: 156-157.

86. A.M.M. A. cap. 21/08/1685.

87. MOROTE, 1741: 58
} 
Como es fácil de deducir a estas alturas, ya en estas últimas décadas del siglo XVII la actividad corsaria había disminuido considerablemente. Quedaban bastante lejos los peligrosos desembarcos y razias de las galeotas berberiscas, tan comunes hasta los años 6o de esa centuria. Algunos factores concatenados, como el traslado de la base de la escuadra de galeras de España a Cartagena, que multiplicó sus acciones de guardacosta en el litoral murciano, la intensa actividad de los corsistas españoles en el Mediterráneo occidental, la destrucción de una buena parte de las armadas berberiscas por las potencias navales cristianas y los terribles bombardeos a los que sometieron a algunas ciudades del norte de África, como Argel, Túnez, Bizerta, Bujía o Cherchel, redujeron de forma notable el potencial depredador de estos puertos corsarios $^{88}$. Esto facilitó, como es obvio, el progreso demográfico de algunas áreas litorales del Mediterráneo ibérico, que en el caso del reino de Murcia se concretó fundamentalmente en la comarca del Mar Menor y en la marina de Mazarrón, toda vez que otros espacios costeros, como es caso de la marina de Lorca o el poniente cartagenero, aún tuvieron que esperar muchos años para iniciar su repoblación.

\section{CONCLUSIONES}

Cuando se inicia la Edad Moderna, el reino de Murcia era uno de los territorios más despoblados de la Península. Su carácter fronterizo durante siglos, tanto terrestre como marítimo, y su localización entre enemigos hostiles, no favoreció el asentamiento de habitantes en la zona meridional, salvo en algunos núcleos urbanos del interior. En su margen litoral la situación era aún más grave y solo sobrevivía el puerto de Cartagena y la pequeña villa minera de Mazarrón, aunque fuertemente amurallados. El resto de la costa era un completo desierto demográfico.

La oportunidad que ofreció el crecimiento europeo del siglo XVI no pudo ser aprovechado aquí debido al aumento extraordinario de la presión corsaria tras el establecimiento de los hermanos Barbarroja en Argel. La expansión de este puerto berberisco a lo largo de esa centuria frenó cualquier intento de repoblación del área ribereña, a pesar del enorme esfuerzo por ganar nuevas tierras, que se materializó en un primer momento en la colonización de algunos parajes cerca de pozos, ramblas y zonas de pasto, los cuales permitieron cierta agricultura de secano y la ganadería trashumante.

Poco a poco los nuevos vecinos, procedentes en su mayor parte del interior del reino y de La Mancha, se fueron asentando cerca de la costa, a pesar de que el peligro corsario, lejos de disminuir, se mantuvo firme hasta las décadas centrales del siglo XVII. Pero, como hemos tratado de demostrar, la acción combinada de las tropas móviles concejiles, los socorros llegados del interior y el establecimiento de una red de torres costeras de defensa y vigía, además de actividad de las galeras cristianas en la costa, sirvió para amortiguar los efectos nocivos de los asaltos corsarios y, en muchos casos, para repeler sus temidos desembarcos. Ello animó a

88. Velasco, 2019: 371-398. 
los nuevos pobladores a instalarse en algunos puntos del litoral abandonados desde la presencia musulmana.

No fue un proceso fácil, como hemos podido ver, pues los progresos fueron lentos y en algunos casos se produjeron retrocesos, sobre todo cuando se destrozaron una buena parte de las torres costeras en la década de I630 y no se restauraron hasta I660-I670. El sistema defensivo quedó maltrecho y los vecinos nuevamente expuestos a las periódicas incursiones.

Con todo, podemos constatar un crecimiento demográfico importante en algunas zonas en las últimas décadas del siglo XVII, como la comarca del Mar Menor, paralelo al que se estaba produciendo en otras áreas litorales de la geografía peninsular. Se trata de un proceso migratorio del interior a la periferia que es necesario abordar más profundamente en futuros estudios.

Nuestro interés aquí se ha centrado especialmente en establecer la fuerte correlación existente entre el crecimiento imparable de la presión corsaria durante más de ciento cincuenta años y el fracaso de la repoblación definitiva de las marinas del reino de Murcia. A resultas de ello quedó un frente litoral con escasísimos núcleos urbanos, algunas aldeas y caseríos diseminados por todo el territorio y, sobre todo, enormes desiertos costeros (marina de Lorca y poniente de Mazarrón y Cartagena) que ni el boom turístico del siglo pasado pudo ocupar. 


\section{BIBLIOGRAFÍA}

Abad Cerdán, Rogelio, «Las almadrabas de Almería», Boletín del Instituto de Estudios Almerienses, $n^{\circ}$ I4, I995-1996, pp. 77-89.

Anaya Hernández, Luis Alberto, Moros en la costa. Dos siglos de corsarismo berberisco en las Islas Canarias (1569-I749), Las Palmas, 2006.

Belhamissi, Moulay, Marine et marins d'Alger (1518-I830), Argel, I996.

BonAfFini, Giuseppe, La Sicilia e i barbareschi. Incursioni corsare e riscatto degli schiavi I570I606, Palermo, I983.

Bono, Salvarote, Corsari nel Mediterraneo. Cristiani e musulmani fra guerra, schiavitù e commercio, Milano, I997.

Buendía Porras, Laureano \& MuÑoz Rodríguez, Julio D., «Nuevos poderes para nuevos espacios. Los diputados de la marina murciana en la vertebración política del territorio (ss. XVII-XVIII)», Murgetana, $\mathrm{n}^{\mathrm{o}}$ I07 (2002), pp. 73-9I.

Buendía Porras, Laureano, «Población y sociedad en Los Alcázares durante la Edad Moderna», Historia de Los Alcázares, t. I, Murcia, 2008, pp. 65-244.

CÁmARA Muñoz, Alicia, «Las torres del litoral en el reinado de Felipe II: una arquitectura para la defensa del territorio», Espacio, Tiempo y Forma, serie VII, t. 3 (I990), pp. 55-86.

Cennamo, Mario, Pirati saraceni e barbareschi in Liguria, Génova, 2004.

Espino López, Antonio, «Los enemigos de la Monarquía en el Mediterráneo: el caso de la defensa de Ibiza en el siglo XVII, I598-I62I», en Investigaciones Históricas, no 26 (2006), pp. II-28.

FeIjoo, Ramiro, Corsarios berberiscos, Barcelona, 2003.

Fenicia, Giuilio, Il Regno di Napoli e la difensa del Mediterraneo nell'età di Filippo II (I556I598). Organizzacione e finanziamento, Bari 2004.

Franco Silva, Alfonso, El alumbre del Reino de Murcia, Murcia, I996.

García Antón, José, Estudios históricos sobre Águilas y su entorno, Murcia, 1992.

Gil Albarracín, Antonio, Documentos sobre la defensa de la costa del reino de Granada (I497I857), Almería-Barcelona, 2004.

Gil Albarracín, Antonio, Vespasiano Gonzaga Colonna y las fortificaciones españolas del siglo XVI, Almería-Barcelona, 2018.

Grandal López, Alfonso, «Un ejemplo de incursión corsaria por la costa murciana: el desembarco de Morato Arráez en Portmán en octubre de I587», Cuadernos del Estero,

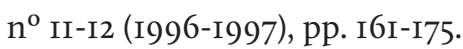

Guerrero Arjona, Melchor, Lorca. De ciudad de frontera a ciudad moderna. Transformaciones políticas, sociales y económicas (1550-1588), Murcia, 2005.

Jiménez de Gregorio, Fernando, El municipio de San Javier en la historia del Mar Menor, Murcia, I984.

GuilléN RiQuelme, Mariano C., Un siglo en la historia de Mazarrón, I462-I572. De la fundación de las Casas de los Alumbres a la concesión del privilegio de Villazgo, Murcia, $200 \mathrm{I}$.

Gutiérrez Nieto, Juan Ignacio, «Evolución demográfica de la cuenca del Segura en el siglo XVI», Hispania, III (I969), pp. 23-II5.

Lemeunier, Guy, «Las actividades pesqueras en la costa murciana, S. XVI-XVII», Nuestra Historia, Cartagena, I987, pp. 225-237.

Lemeunier, Guy \& Pérez Picazo, María T., El proceso de modernización de la región murciana, Murcia, I984. 
Martínez Ruiz, Enrique, Los soldados del rey. Los ejércitos de la Monarquía Hispánica (I480I700), Madrid, 2008.

Mesa Coronado, María del Pilar, «La isla de Candía en la diplomacia Hispano-Veneciana (I665-I669)». Investigaciones Históricas, 34 (2014), pp. 8I-I05.

Molına Molına, Ángel Luis, El campo de Murcia en el siglo XV, Murcia, I989.

Montojo Montojo, Vicente, Cartagena en la época de Carlos V, Murcia, 1987.

Montojo Montojo, Vicente, «Introducción al estudio de las estructuras agrarias en Cartagena a principios de la Edad Moderna», Contrastes, no 3-4 (1987-I988), pp. 7-25.

Montojo Montojo, Vicente, El Siglo de Oro en Cartagena (I480-I640), Murcia, 1993.

Montojo Montojo, Vicente, «La torre de Los Alcázares: de antiguo palacio a lugar de defensa. Siglos XV-XVIII», en Historia de Los Alcázares, t. I, Murcia, 2008, pp. 4I-64.

Morote, Pedro, Blasones y antigüedades de la ciudad de Lorca, Murcia, I74I (ed. I980).

Pardo Molero, Juan Francisco, La defensa del Imperio: Carlos V, Valencia y el Mediterráneo, Madrid, 200I.

Pérez de Colosia, María Isabel \& SARriá MuÑoz, Andrés, «Las almadrabas del duque de Medina Sidonia en Tarifa», Baetica, I3, I99I, pp. 24I-254.

ReQuena Amoraga, Francisco, La defensa de las costas valencianas en la época de los Austrias, Alicante, 1997.

ReQuena Amoraga, Francisco, El corso turco-berberisco en la Gobernación de Orihuela (siglos $X V I-X V I I)$, Elche, 200I.

Rodríguez Llopis, Miguel, Historia de la Región de Murcia, Murcia, I999.

Rubio Paredes, José María, Historia de las torres vigías de la costa del reino de Murcia (ss. XVI-XIX), Murcia, 2000.

Ruiz lbáñez, José Javier, Las dos caras de Jano. Monarquía, ciudad e individuo. Murcia, I588I648, Murcia, I995.

Ruiz IbáÑ̃z, José Javier y Montojo Montojo, Vicente, Entre el lucro y la defensa. Las relaciones entre la monarquía y la sociedad mercantil cartagenera (Comerciantes y corsarios en el siglo XVII), Murcia, I998.

Ruız IвÁÑEZ, José Javier, «Las milicias del rey de España», Las milicias del rey de España: sociedad, política e identidad en las Monarquías Ibéricas, Madrid, 2009, pp. 29.

Ruiz Martín, Felipe, Los alumbres españoles. Un índice de la coyuntura económica europea en el siglo XVI, Madrid, 2005.

Russo, Flavio, Le torri costiere del regno di napoli. la frontiera marittima e le incursioni corsare tra il XVI ed il XIX secolo, Nápoles, 2009.

SÁnchez BelÉn, Juan Antonio \& AlCARAZ Hernández, Antoinette T., «Oligarquía municipal e impuestos: la asonada del campo de Cartagena de I683", Espacio, Tiempo y Forma, serie IV, $\mathrm{n}^{\circ} 4$ (1991), pp. I63-202.

Sebag, Paul, Tunis au XVIle siècle. Una cité barbaresque au temps de la course, París, I989.

Seguí Beltrán, Andreu, «El corso en Baleares en el siglo XVl», Drassana, 23 (2015), pp. 143-I58.

Tinniswood, Adrian, Pirates of Barbary: corsairs, conquests, and captivity in the seventeenthcentury Mediterranean, New Cork, 2010.

Torres Fontes, Juan, «La torre de Los Alcázares», Anuario de Prehistoria y Arqueología, ${ }^{\circ}$ 5-6 (I989-I990), pp. I83-I88.

Torres SÁnchez, Rafael, Ciudad y población. El desarrollo demográfico de Cartagena durante la Edad Moderna, Cartagena, I998.

Velasco Hernández, Francisco, Auge y estancamiento de un enclave mercantil en la periferia: El nuevo resurgir de Cartagena entre 1540 y I676, Murcia, 200I. 
Velasco Hernández, Francisco, «La sosa-barrilla una seña de identidad del Campo de Cartagena en los siglos XVI al XIX», Revista Murciana de Antropología, ro (2004), pp. I45-I58.

VeLASCO HeRnÁNDEZ, Francisco, «La razzia del corsario Morato Arráez en la costa murciana en agosto de I602», Murgetana, $\mathrm{n}^{\circ}$ I25 (201I), pp. 83-IOI.

Velasco Hernández, Francisco, «Cinco torres para un reino: los proyectos de Felipe Il para fortificar la costa murciana (1570-1580)», Cartagena Histórica, 39 (2012), pp. Io-25.

Velasco Hernández, Francisco, «La defensa de la costa de Lorca y Mazarrón en el siglo XVI», Felipe Il y Almazarrón: La construcción local de un Imperio global, Murcia, 20I4, pp. 235-248.

Velasco Hernández, Francisco, «Las galeras del corsario Alí Bitchín y sus campañas de saqueo en las costas de Alicante y Murcia durante la década de I630», Revista de Historia Moderna, ${ }^{\circ} 33$ (2015), pp. 163-185.

Velasco Hernández, Francisco, Corsarismo, piratería y guerra costera en el sureste español. El acoso turco berberisco a las costas de Alicante, Murcia y Almería, Cartagena, 2019. 


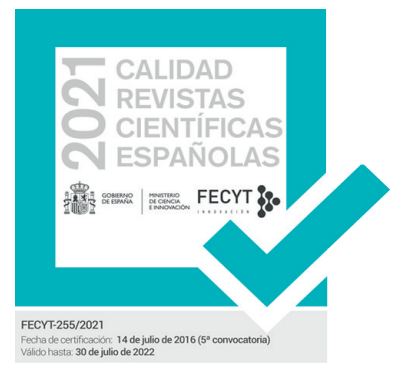

SERIE IV HISTORIA MODERNA

REVISTA DE LA FACULTAD DE GEOGRAFÍA E HISTORIA

AÑO 2021

ISSN: 1131-768X

E-ISSN 2340-1400

\section{4 \\ 西 ESPACIO, TIEMPO Y FORMA}

Monográfico - Special Issue: La política ultramarina de las monarquías ibéricas (circa 1700-1750): una historia de fracasos y éxitos relativos The Overseas Policy of the Iberian Monarchies (Circa 1700-1750): A History of Failures and Relative Successes

15 Roberto Quirós Rosado y MARIA FERnANDA BICALHO La política ultramarina de las monarquías ibéricas (circa 1700-1750): una historia de fracasos y éxitos relativos / The Overseas Policy of the Iberian Monarchies (Circa 1700-1750): A History of Failures and Relative Successes

\section{Guillaume Hanotin}

Defender negocios en tiempo de convulsión política: las elites mercantiles francesas durante la guerra de Sucesión española / Protecting Business in Time of Crisis: French Trademen during the War of Spanish Succession

\subsection{Maria Fernanda Bicalmo}

Ultramarino y el auge de los secretarios de Estado en Portugal durante la primera mitad del siglo XVIII / Sobre este modo de resolver e despachar os negócios. The decline of the Overseas Council and the Rise of the Secretaries of State in Portugal during the First Half of the $18^{\text {th }}$ Century

\section{9}

\section{VALENTINA FAVARò}

El fracaso de los proyectos de reforma en el virreinato peruano de principios

del siglo XVIII. Las propuestas de Carmine Nicola Caracciolo, príncipe de Santobuono the Eighteenth Century. The Proposals of Carmine Nicola Caracciolo, Prince of Santobuono

\section{7}

\section{ROBERTO QUIRÓS ROSADO}

Ecos de un mercantilismo truncado. El conde de Pinos Puente y la diplomacia comercial de Carlos VI en la corte de Lisboa (1723-1724) / Echoes of a Failed Mercantilism. The Count of Pinos Puente and the Commercial Diplomacy of Charles VI at the Court Of Lisbon (1723-1724)

\section{Junia Ferreira Furtado}

Portuguese America under Foreign Threat and the Creation of the Concept of uti possidetis in the First Half of the $18^{\text {th }}$ Century / La américa portuguesa bajo la amenaza exterior y la creación del concepto de uti possidetis en la primera mitad del siglo XVIII

\section{Miscelánea $\cdot$ Miscellany}

\section{JosÉ Antonio Mateos Royo}

con Cataluña / Trade Policy and Monetary Circulation in Aragon: Conflicts and Agreements with Catalonia (1535-1565)

\section{Fernando Altoé}

panegíricos atribuidos a la impresion. Un estudio de la trayectoria de dos the Trajectory of Two Panegyrics Attributed to João de Barros

\section{Francisco Velasco Hernández}

reino de Murcia (siglos XVI y XVII) / The Influence of the Berber Corsican on the Late Repopulation on the Coastal Area on the Kingdom of Murcia (XVI and XVII Centuries)

\section{José Antonio Martínez Martínez}

Criados, jornaleros y esclavos al servicio de la familia: la servidumbre de Serfdom of the Muñoz de Otálora in the $17^{\text {th }}$ Century

\section{Víctor Daniel Regalado González-Serna}

Benito de Medina a raíz de su ingreso en el cabildo catedral de Sevilla en 1669 / «Not a Single Good Portuguese». Accusations against Priest Alonso Benito de Medina when Entering the Cathedral Chapter of Seville in 1669

\section{José Herrera Reviriego}

organigrama comercial y militar de la Gober mitad del siglo XVII / "Only Time will Tell us»: The Role of Taiwan within the Commercial and Military Organization of the Philippine's Governoration during the First Half of the Seventeenth Century

\section{Manuel-Reyes García Hurtado}

de Rande, 1719-1733 / Vicissitudes of the Rescue Companies of the Sunken Ships in the Battle of Rande, 1719-1733

\subsection{Marcos de Miguel MuÑoz}

Caballeros in 1769 


\section{4 ESPACIO, TIEMPO Y FORMA}

\section{Javier Tinoco Domínguez}

Tensiones sociopolíticas en el marco del catastro de Fnsenada en Jerez de la Frontera: estudio de un conflicto institucional / Socio-Political Tensions within the Framework of Cadastre of Ensenada In Jerez de la Frontera: A Studying of an Institucional Conflict

\section{Pablo Fernández Albaladejo}

Fábulas de origen y gramática de nación en la España del siglo XVIII. A propósito de algunos trabajos de Francisco Martínez Marina / Origin's Fables and Grammar of Nation in the XVIII Century Spain. About some Works by Francisco Martínez Marina

\subsection{José María IÑURRITEgui Rodríguez}

3 Constitución increada: Francisco Martínez Marina y la crítica bíblica / Uncreated Constitution. Francisco Martínez Marina and Biblical Criticism

\subsection{David A. Abián Cubillo}

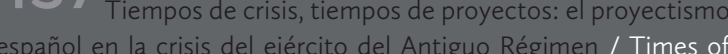
crisis, Times of Projects: The Spanish proyectismo during the Army's Crisis in the Ancient Regime

Taller de historiografía · Historiography Workshop

Ensayos · Essays

\subsection{Christoph ROSEnMüLler}

«Tan peligrosas y feas conspiraciones»: la relación escrita por el embajador austriaco Christoph Migazzi en 1754 sobre la caída del marqués de la Ensenada / «Dangerous and Ugly Conspiracies». The Report of the Austrian Ambassador Christoph Migazzi on the Fall of the Marquis of la Ensenada in 1754

\subsection{Serge Gruzinskı}

Quelle histoire enseigner en 2021 ? / ¿Qué historia enseñar en 2021?

\subsection{Carlos Amate Pizarro}

Las relaciones hispano-chinas en el siglo XVI: síntesis e interpretación a la luz de la reciente historiografía / The Hispanic-chinese Relationship in the XVI Century: Synthesis and Interpretation in the Light of Recent Historiography

\section{Reseñas • Book Review}

521 Bolufer Peruga, Mónica, Arte y artificio de la vida en común. Los modelos de comportamiento y sus tensiones en el Siglo de las Luces, (Julio ArRoyo VozmediANo) 


\section{4 ESPACIO, TIEMPO Y FORMA}

525 Melón, Amando, Alejandro de Humboldt. Vida y obra (Carlos Martínez Shaw)

52 Commentary to Tatiana Seijas' review of The Atlantic World and the Manila Galleons: Circulation, Market, and Consumption of Asian Goods in the Spanish Empire (JosÉ LuIs GASCH TOMAS)

533 Braguier, Laurey, Servantes de dieu. Les beatas de la Couronne de Castille (1450-1600) (Manuela Águeda GARCÍA-GARRIDO)

539 Romeo, María CRuz; SAlomón, María Pilar; TABANERA, Nuria (eds.): Católicos, Reaccionarios y Nacionalistas. Política e identidad nacional en Europa y América Latina Contemporáneas (JAVIER M. Dos SANTOS)

54 Heredia López, Alfonso Jesús, El control de la corrupción en la Monarquía Hispánica. La Casa de la Contratación (1642-1660) (José Manuel Díaz Blanco)

17 Andújar Castillo, Francisco, El Atila de Madrid. La forja de un banquero en la crisis de la monarquía (1685-1715) (Aitor Díaz PAREdes)

551 Serrano Aviles, Javier y Mojarro, Jorge (eds.) Prada GonzALEZ, María (coord. de ilustraciones), En el archipiélago de la Especiería. España y Molucas en los siglos XVI y XVII (İ̃̃ıGo VALPUESTA VILLA)

555 Díaz Ceballos, Jorge, Poder compartido. Repúblicas urbanas, Monarquía y conversación en Castilla del Oro, 1508-1573 (JUAN SEbAstián Gómez GonZÁleZ)

51 Edelmayer, Friedrich, Massimiliano II, Filippo II I'Italia imperiale. II marchesato di Finale, i diritti imperiali e il «camino spagnolo» (RAFAEL VALLADARES)

56 Escribano-PÁEZ, José M., Juan Rena and the Frontiers of Spanish Empire, 1500-1540 (DAvid Martín Marcos)

56 ARnOLD, David, La Era de los Descubrimientos (1400-1600), Madrid, Alianza Editorial, 2021, 184 Pp., ISBN: 978-841362-172-2 (CARlos Amate Pizarro) 